\title{
Investigation of the Products of Heavy Hypernuclei
}

\author{
Süleyman ÖZTÜRK¹, Nihal BÜYÜKÇİZMECI'²* \\ *Corresponding Author: nihal@selcuk.edu.tr \\ ${ }^{1}$ Selcuk University, Faculty of Science, Department of Physics, 42130, KONYA \\ Orcid No: 0000-0002-4344-3026/fizikcik@hotmail.com \\ ${ }^{2}$ Selcuk University, Faculty of Science, Department of Physics, 42130, KONYA \\ Orcid No: 0000-0002-6030-9574/nihal@selcuk.edu.tr
}

\begin{abstract}
Evaporation of hypernuclei is investigated similar to evaporation of normal nuclei taking place in deep-inelastic nuclear collisions. Final cold hypernuclei can be obtained in such processes and offer a new direction for investigation. This may concern the production of exotic states which can exist due to the presence of a hyperon. It will be difficult to obtain such exotic states in other reactions since there are practical limitations on the use of radioactive targets in experiments. We have investigated the evaporation mechanism of some heavy hypernuclei for emission of light hypernuclei which take place from the target and projectile residues. Theoretical calculations are carried out by using computer codes developed for the statistical multifragmentation model generalized to hypernuclei.
\end{abstract}

Keywords: Evaporation, Hypernuclei, Statistical Multifragmentation Model

\section{Ağır Hiperçekirdeklerin Ürünlerinin Araştırılması}

Öz: Hiperçekirdeklerin buharlaşması, derin esnek olmayan nükleer çarpışmalarda meydana gelen normal çekirdeklerin buharlaşmasına benzer şekilde incelenmiştir. Son soğuk hiperçekirdekler bu tür işlemlerde elde edilebilir ve araştırma için yeni bir yön sunar. $\mathrm{Bu}$, bir hiperonun varlığından dolayı var olabilecek egzotik durumların üretimiyle ilgili olabilir. Deneylerde radyoaktif hedeflerin kullanımında pratik sınırlamalar olduğundan, diğer reaksiyonlarda bu tür egzotik durumları elde etmek zor olacaktır. Hedef ve mermi kalıntılarından meydana gelen hafif hiperçekirdeklerin emisyonu için bazı ağır hiperçekirdeklerin buharlaşma mekanizmasını araştırdık. Teorik hesaplamalar, hiperçekirdeklere genelleştirilmiş istatistiksel çoklu parçalanma modeli için geliştirilen bilgisayar kodları kullanılarak yapılmıştır.

Anahtar Kelimeler: Buharlaşma, Hiperçekirdekler, İstatistiksel Çok Katlı Parçalanma Modeli

\section{Introduction}

The production of nuclear fragments in relativistic nuclear reactions is one of the important topics in nuclear physics. It is known since the late 1970 s that many different light complex nuclei can be produced in central and peripheral nucleusnucleus collisions. A lot of experiments was devoted to this study associated with the nuclear liquid-gas type phase transition. In particular, ALADIN (Kreutz et al., 1993; Botvina et al., 1995; Xi et al., 1997; Ogul et al., 2011), EOS (Scharenberg et al., 2001), ISIS (Viola et al., 2001; Pienkowski et al., 2002), FASA (Karnaukhov et al., 2008) and other experimental collaborations have provided very high-quality data. In the literature, many dynamic and statistical models were developed for the theoretical scope. The success of the hybrid approaches 
which include the descriptions of the nonequilibrium dynamical reaction stage and the following decay of the equilibrated nuclear sources is well known. The description of the last stage with the statistical models such as SMM (Bondorf et al., 1995) and MMMC (Li et al., 1993) was very instructive. The success of the statistical models in the description of the fragment production has encouraged to generalize them for hypernuclear matter, and, finally, for the production of hypernuclei (Botvina and Pochodzalla, 2007). The involvement of hyperons $(\lambda, \Sigma$, $\Omega, \Xi)$ obtained in high-energy reactions provides a complementary method to improve traditional nuclear studies and opens new horizons for studying particle physics and nuclear astrophysics (Hashimoto et al., 2006; Schaffner et al., 1993; Gal et al., 2012; Buyukcizmeci et al., 2013).

\section{Material and Methods}

In this study, we have used the statistical multifragmentation model which is modified for single and multi-Lambda nuclei and called as hyper-SMM (Botvina and Pochodzalla, 2007; Buyukcizmeci et al., 2013; 2018; 2019; 2020; Botvina et al., 2016).

In the Grand Canonical approach, average yields of individual fragments $\mathrm{Y}_{\mathrm{A}, \mathrm{Z}, \mathrm{H}}$ is given as follows:
$g_{\mathrm{A}, \mathrm{Z}, \mathrm{H}} \cdot V_{\mathrm{f}} \cdot \frac{A^{3 / 2}}{\lambda_{T}^{3}} \cdot \exp \left\{-\frac{1}{T}\left(-\left(F_{\mathrm{A}, \mathrm{Z}, \mathrm{H}}-\mu_{\mathrm{A}, \mathrm{Z}, \mathrm{H}}\right)\right\}\right.$,

and where $\mu_{\mathrm{A}, \mathrm{Z}, \mathrm{H}}=\mathrm{A} \mu+\mathrm{Zv}+\mathrm{H} \xi$, with A mass (baryon) number, charge $Z$, and the $\Lambda$-hyperon number $H . \quad T$ is the temperature, $F_{\mathrm{A}, \mathrm{Z}, \mathrm{H}}$ is the internal free energies of these fragments, $V_{\mathrm{f}}$ is the free volume available for the translation motion of the fragments, $g_{A, Z, H}$ is the spin degeneracy factor of species $(\mathrm{A}, \mathrm{Z}, \mathrm{H}), \lambda_{T}=$ $\left(2 \pi \hbar^{2} / m_{N} T\right)^{1 / 2}$ is the baryon thermal wavelength, $\mathrm{m}_{\mathrm{N}}$ is the average baryon mass. The chemical potentials $\mu, v$, and $\xi$ are responsible for the mass number, charge, and strangeness conservation in the system, and they can be numerically found from the corresponding conservation laws accounting for the total baryon number $A_{0}$, the total charge number $\mathrm{Z}_{0}$, and the total hyperon number $\mathrm{H}_{0}$ in the system. In this model the statistical ensemble includes all break-up channels include baryons and excited fragments. The primary fragments are formed in the freeze-out volume $V . V=$ $V_{0}+V_{f}$, where $V_{0}=A_{0} / \rho_{0} \quad\left(\rho_{0} \cong 0.15 \mathrm{fm}^{-}\right.$ ${ }^{3}$ ), and $V_{f}=K . V_{0}$ is the free volume, with $K \cong 2$, as similar in experiments. The binding energy $E_{A}^{b h}$ of one hyperon at the temperature $T$ inside a hypernucleus with $(\mathrm{A}, \mathrm{Z}, \mathrm{H})$ is defined as $E_{A}^{b h}=F_{\mathrm{A}, \mathrm{Z}, \mathrm{H}}-$ $\mathrm{F}_{\mathrm{A}-1, \mathrm{Z}, \mathrm{H}-1}$. In this work we consider the generalization of the evaporation developed 
in Refs. (Bondorf et al., 1995; Botvina et al., 1987; Buyukcizmeci et al., 2005) and extended version for hypermatter (Botvina et al., 2016, Botvina and Pochodzalla, 2007, Buyukcizmeci et al., 2013, 2018, 2019, 2020).

\section{Results and Discussion}

We have carried out calculations to compare the size effect of the different nuclei and hypernuclei over million events. In Fig. 1 and Fig. 2, we consider initial masses of nuclei and hypernuclei systems $\left(A_{0}=100\right.$, and 165$)$ that can be naturally produced after the dynamical stage and with different isospins. Mass distributions are compared to show the evolution of produced and evaporated nuclei from normal and heavy hypernuclei for temperatures $\mathrm{T}=2-6$ $\mathrm{MeV}$. This temperature range was adopted in order to investigate the region of coexistence of big and small fragments, typical for liquid-gas-type phase transition in finite systems, which is also observed in multifragmentation reactions (Botvina and Pochodzalla, 2007; Ogul et al., 2011; Scharenberg et al., 2001; Buyukcizmeci et al., 2013). The evolution of the mass distributions with temperature is compared in the present work for $A_{0}=100$ and $A_{0}=165$ nuclei: At a low temperature $(T=2-3 \mathrm{MeV})$ we have a "U-shape" distribution, at the lightest (nucleons and light clusters) and largest to the system size fragments, and the "valley" in between. The yield of intermediate-mass fragments increases with increasing temperature and at about $T=4$ $\mathrm{MeV}$ we see a "plateau"-like distribution. At higher temperatures ( $\mathrm{T} \geq 5$ ) we will have an exponential decrease in yield with mass number as established in multifragmentation reactions with normal nuclei. At moderate temperatures, hyperons are predominantly accumulated in big fragments because of the high binding energy. At low temperatures, when the largest nuclei survive, one can be sure that they contain practically all the Lambda's of the system. In Fig. 2, at higher temperatures $(T \geq 5)$ one can see a steeper behavior of exponential decay in yield with the mass number due to the larger initial source can decay more easily.

We have presented fragment yields of normal Carbon and Nitrogen isotopes emitted from initially excited nuclei with $A_{0}=100, Z_{0}=40, H_{0}=4$ and $A_{0}=200, Z_{0}=80$, $H_{0}=4$ system around at $T=4 \mathrm{MeV}$ in Fig. 3 similar as in Ref. (Buyukcizmeci et al., 2020). The larger initial source gives a larger probability for the yield production since it is more neutron-rich even if $\mathrm{N} / \mathrm{Z}$ ratios are similar, in this way, we have verified the size effect of the initial source for the reproduction of yields. As a further step in Fig. 4, we demonstrate the results for relative yields of $14 \mathrm{~N}, 14{ }_{\Lambda} \mathrm{N}, 14_{\Lambda} \mathrm{N}$, 


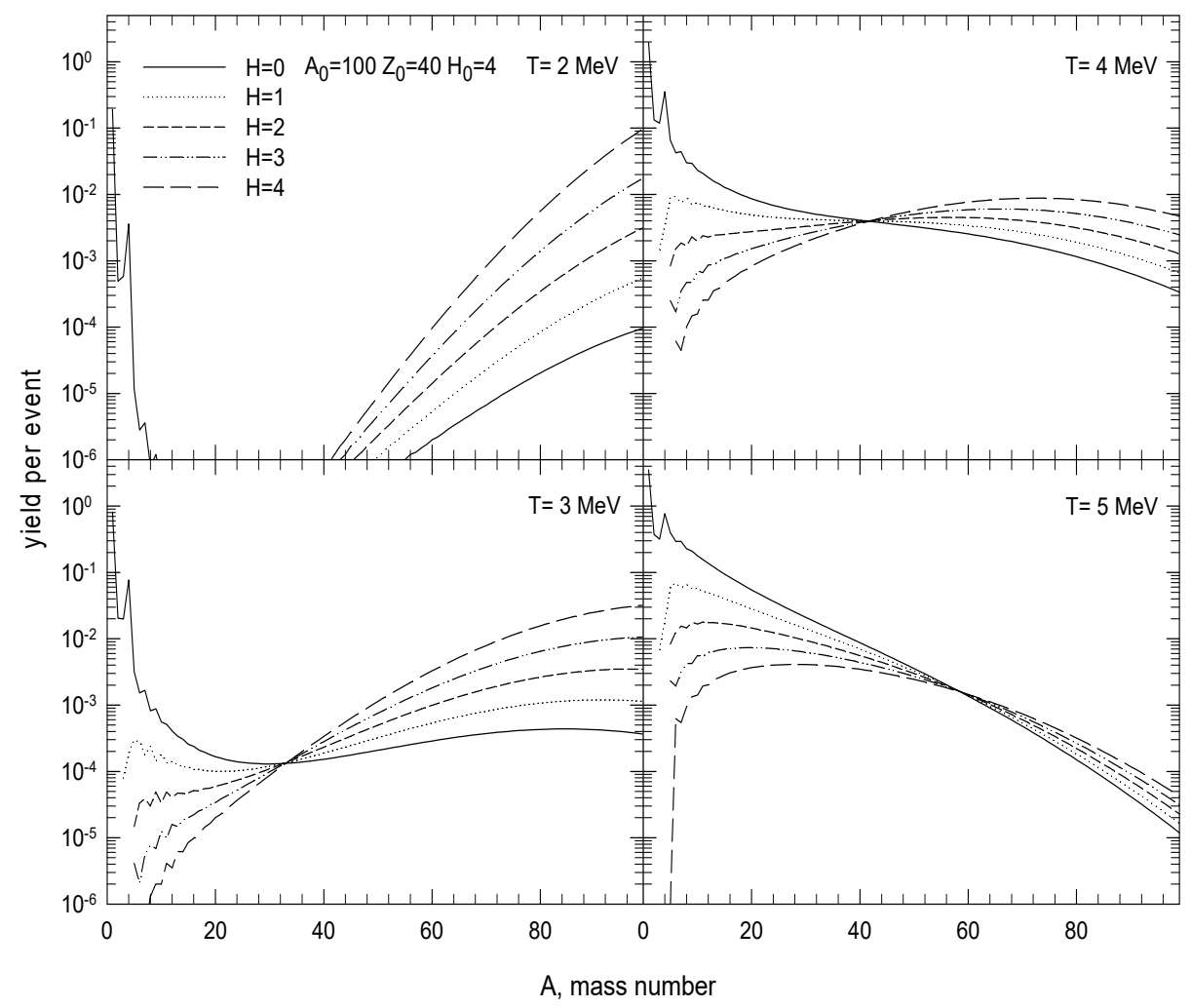

Figure 1. SMM predictions of total yields per event versus their mass number, after the disintegration of excited systems containing four $\Lambda$ hyperons. Initial mass number $A 0=100$, charge number $Z 0=40$, hyperon number $H 0=4$, and temperatures $T$ of the systems are shown. Lines are calculations for fragments with a certain number of $\Lambda$ hyperons.

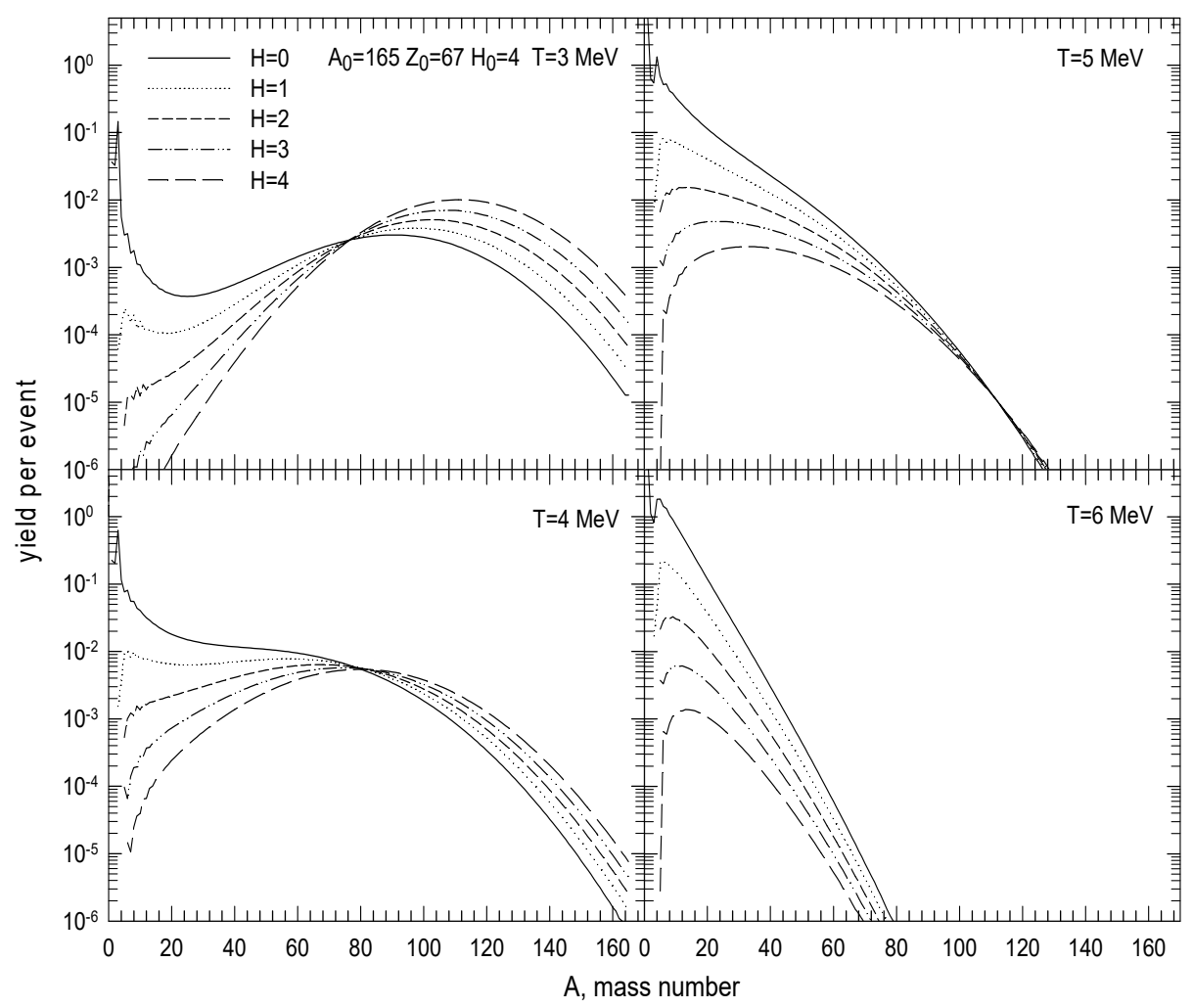

Figure 2. The same as Fig. 1 , but for $A 0=165, Z 0=67$ and $H 0=4$, neutron-rich system. 


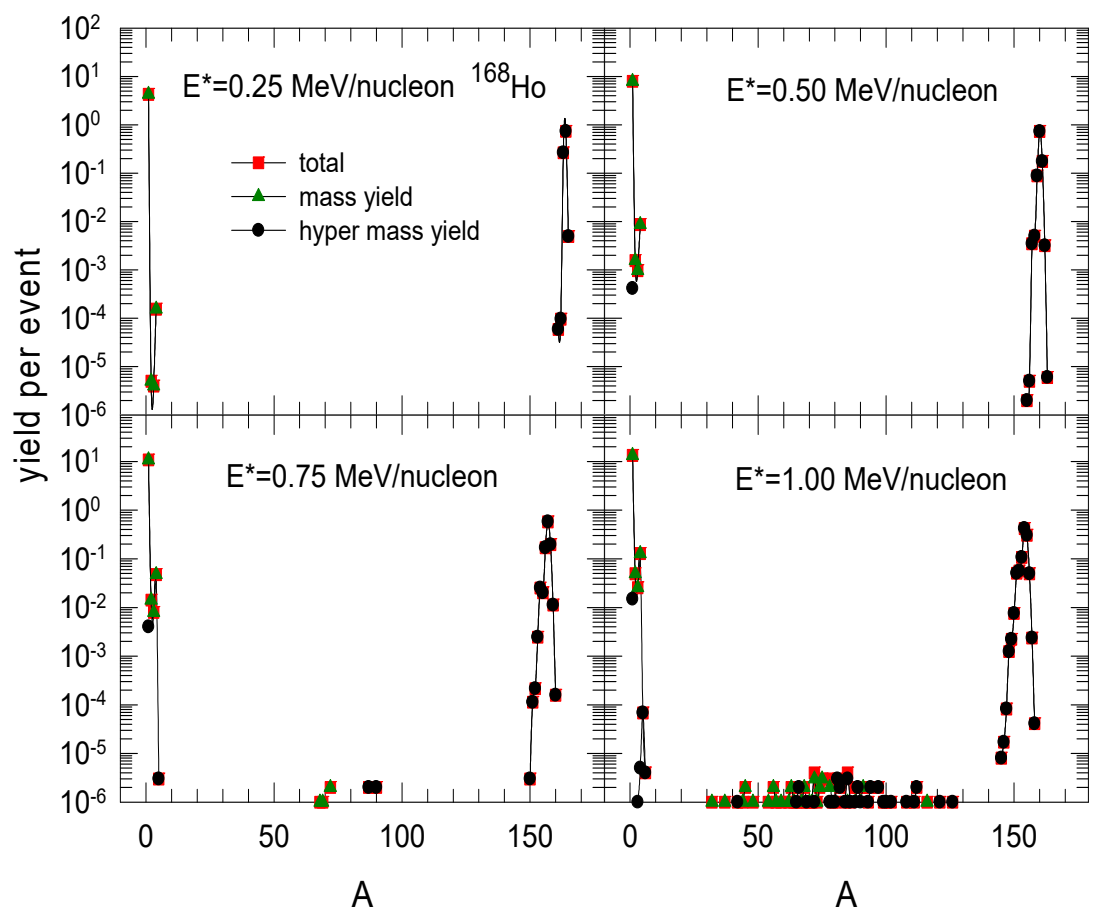

Figure 2. The same as Fig. 1, but for $A_{0}=168, Z_{0}=67$ and $H_{0}=4$ source nucleus.

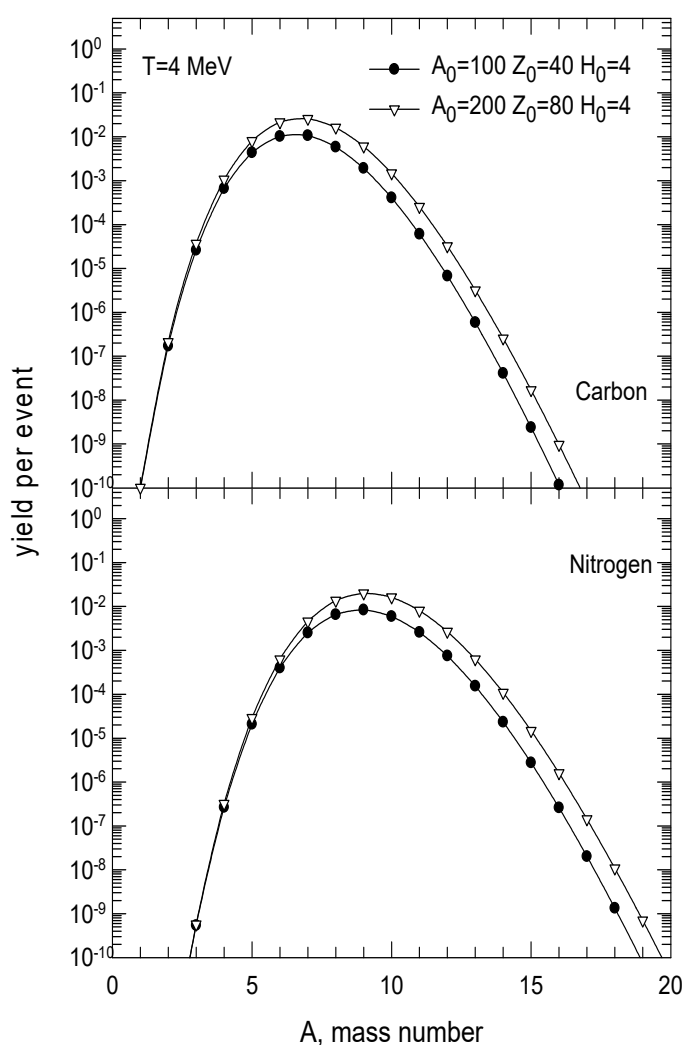

Figure 3 Relative yields of Carbon (top panel) and Nitrogen isotopes (bottom panel) as a function of their mass number, after the decay of excited initial nuclei with $\mathrm{A}_{0}=100, \mathrm{Z}_{0}=40$ (full symbols) and $\mathrm{A}_{0}=200, \mathrm{Z}_{0}=80$ (open symbols), at $\mathrm{T}=4 \mathrm{MeV}$.

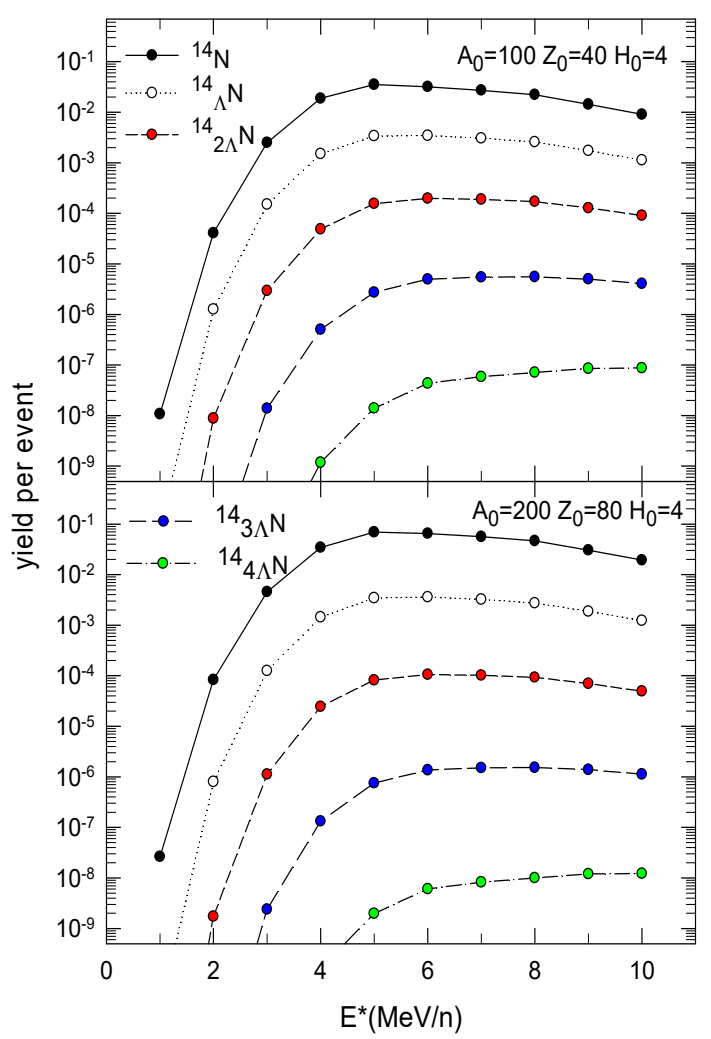

Figure 4 Isotope yields of Nitrogen isotopes produced after decay of an excited hypernuclear system at different excitation energies. Top panel shows the results for $\mathrm{A}_{0}=100, \mathrm{Z}_{0}=40$, and bottom 
$14_{3 \Lambda} \mathrm{N}$, and $14_{4 \Lambda} \mathrm{N}$ isotopes as a function of excitation energies for both initial source systems. The ordered distributions of the yields from normal nuclei with higher probability to hypernuclei. While the relative yields of normal and hyper-Carbon isotopes show an increasing trend up to 3-4 $\mathrm{MeV} /$ nucleon, they show almost a flat distribution after 5-6 MeV/nucleon. We hope that our theoretical findings would be realized in future experiments at intermediate energies, at FAIR (Darmstadt) and NICA (Dubna).

\section{Acknowledgement}

Many helpful discussions with AS Botvina, R Ogul and A Kaya are gratefully acknowledged. This study is prepared from Master Thesis of S Ozturk at Graduate School of Natural Science of Selcuk University, supported by Scientific and Technological Research Council of Turkey (TUBITAK), under Project No. 118F111, and has been performed in the framework of COST Action CA15213 THOR.

\section{References}

Bondorf JP, Botvina AS, Iljinov AS, Mishustin IN, Sneppen K (1995). Statistical multifragmentation of nuclei. Phys Rep 257: 133-221.

Botvina AS, Mishustin IN, Begemann-Blaich M, Hubele J, Imme G, Iori I, Kreutz P, Kunde GJ, Kunze WD, Lindenstruth V, Lynen U, Moroni A, Müller WFJ, Ogilvie CA, Pochodzalla J, Raciti J, Rubehn Th, Sann H, Schüttauf A, Seidel W, Trautmann W, Wörner A (1995). Multifragmentation of spectators in relativistic heavy-ion reactions. Nucl Phys A 584(4): 737-756.

Botvina AS, Buyukcizmeci N, Ergun A, Ogul R, Bleicher M, Pochodzalla J (2016). Formation of hypernuclei in evaporation and fission processes. Phys Rev C 94: 054615.

Botvina AS, Pochodzalla J (2007). Production of hypernuclei in multifragmentation of nuclear spectator matter. Phys Rev C 76: 024909.

Buyukcizmeci N, Botvina AS, Ergun A, Ogul R, Bleicher M (2018). Statistical production and binding energy of hypernuclei. Phys Rev C 98: 064603.

Buyukcizmeci N, Botvina AS, Ogul R, Ergun A, Bleicher M (2019). Production of $\Lambda \Lambda$ hypernuclei and evaluation of their binding energies via the double yield ratio. Eur Phys $J$ A 55(2): 1.

Buyukcizmeci N, Botvina AS, Pochodzalla J, Bleicher M (2013). Mechanisms for the production of hypernuclei beyond the neutron and proton drip lines. Phys Rev C 88: 014611.

Buyukcizmeci N, Ogul R, Botvina AS (2005). Isospin and symmetry energy effects on nuclear fragment production in liquid-gas-type phase transition region. Eur Phys $J$ A 25: $57-64$.

Buyukcizmeci N, Ogul R, Botvina AS, Bleicher M (2020). On the survey of nuclei and hypernuclei in multifragmentation. Phys Scr 95: 075311.

Gal A, Hashimoto O, Pochodzalla J (Editors) (2012). Special issue on progress in strangeness nuclear physics. Nucl Phys A 881: 1-338.

Hashimoto O, Tamura H (2006). Spectroscopy of $A$ hypernuclei. Prog Part Nucl Phys 57: 564. 
Karnaukhov VA, Oeschler H, Budzanowski A, Avdeyev SP, Botvina AS, Cherepanov EA, Karcz W, Kirakosyan VV, Rukoyatkin PA, Skwirczyńska I, Norbeck E (2008). Critical temperature for the nuclear liquid-gas phase transition (from multifragmentation and fission). Phys Atom Nuclei 71: 2067.

Kreutz P, Adioff JC, Begemann-Blaich M, Bouissou P, Hubele J, Imme G, Iori I, Kunde GJ, Leray S, Lindenstruth V, Liu Z, Lynen U, Meijer RJ, Milkau U, Moroni A, Müller WFJ, Ngô C, Ogilvie CA, Pochodzalla J, Raciti G, Rudolf G, Sann H, Schüttauf A, Seidel W, Stuttge L, Trautmann W, Tucholski A (1993). Charge correlations as a probe of nuclear disassembly. Nucl Phys A 556(4): 672-696.

Li BA, DeAngelis AR, Gross DHE (1993). Statistical model analysis of ALADIN multifragmentation data. Phys Lett B 303: 225.

Ogul R, Botvina AS, Atav U, Buyukcizmeci N, Mishustin IN, Adrich P, Aumann T, Bacri CO, Barczyk T, Bassini R, Bianchin S, Boiano C, Boudard A, Brzychczyk J, Chbihi A, Cibor J, Czech B, De Napoli M, Ducret JÉ, Emling H, Frankland JD, Hellström M, Henzlova D, Immè G, Iori I, Johansson H, Kezzar K, Lafriakh A, Le Fèvre A, Le Gentil E, Leifels Y, Lühning J, Łukasik J, Lynch WG, Lynen U, Majka Z, Mocko M, Müller WFJ, Mykulyak A, Orth H, Otte AN, Palit R, Pawłowski P, Pullia A, Raciti G, Rapisarda E, Sann H, Schwarz C, Sfienti C, Simon H, Sümmerer K, Trautmann W, Tsang MB, Verde G, Volant C, Wallace M, Weick H, Wiechula J, Wieloch A, Zwiegliński B (2011). Isospin-dependent multifragmentation of relativistic projectiles. Phys Rev C 83(2): 024608.

Pienkowski L, Kwiatkowski K, Lefort T, Hsi WC, Beaulieu L, Viola VE, Botvina A, Korteling RG, Laforest R, Martin E, Ramakrishnan E, Rowland D, Ruangma A, Winchester E, Yennello SJ, Back B, Breuer H, Gushue S, Remsberg LP (2002). Breakup time scale studied in the $8 \mathrm{GeV} / \mathrm{c} \pi-+197 \mathrm{Au}$ reaction. Phys Rev C 65(6): 064606.

Schaffner J, Dover CB, Gal A, Greiner C, Stoecker H (1993). Strange hadronic matter. Phys Rev Lett 71: 1328.

Scharenberg RP, Srivastava BK, Albergo S, Bieser F, Brady FP, Caccia Z, Cebra DA, Chacon AD, Chance JL, Choi Y, Costa S, Elliott JB, Gilkes ML, Hauger JA, Hirsch AS, Hjort EL, Insolia A, Justice M, Keane D, Kintner JC, Lindenstruth V, Lisa MA, Matis HS, McMahan M, McParland C, Müller WFJ, Olson DL, Partlan MD, Porile NT, Potenza R, Rai G, Rasmussen J, Ritter HG, Romanski J, Romero JL, Russo GV, Sann H, Scott A, Shao Y, Symons TJM, Tincknell M, Tuvé C, Wang S, Warren P, Wieman HH, Wienold $\mathrm{T}$, Wolf $\mathrm{K}$ (2001). Comparison of $1 \mathrm{AGeV} 197 \mathrm{Au}+\mathrm{C}$ data with thermodynamics: The nature of the phase transition in nuclear multifragmentation. Phys Rev C 64(5): 054602.

Viola VE, Lefort T, Beaulieu L, Kwiatkowski K, Wang G, De Souza R, Pienkowski L, Botvina A, Breuer H, Durand D, Korteling RG, Laforest R, Martin E, Ramakrishnan E, Rowland D, Ruangma A, Winchester E, Yennello SJ (2001). Signals for the transition from liguid to gas in hot nuclei. Nucl Phys A 681(1-4): 267-274.

Xi H, Odeh T, Bassini R, Begemann-Blaich M, Botvina AS, Fritz S, Gaff SJ, Groß C, Immé G, Iori I, Kleinevoß U, Kunde GJ, Kunze WD, Lynen U, Maddalena V, Mahi M, Möhlenkamp T, Moroni A, Müller WFJ, Nociforo C, Ocker B, Petruzzelli F, Pochodzalla J, Raciti G, Riccobene G, Romano FP, Rubehn TH, Saija A, Schnittker M, Schüttauf A, Schwarz C, Seidel W, Serfling V, Sfienti C, Trautmann W, Trzcinski A, Verde G, Wörner A, Zwieglinski B (1997). Breakup temperature of target spectators in ${ }^{197} \mathrm{Au}+{ }^{197} \mathrm{Au}$ collisions at $\mathrm{E} / \mathrm{A}=1000 \mathrm{MeV}$. Z Phys A 359: 397-406. 